\title{
3,3'-Bicarbazole-Based Host Molecules for Solution-Processed Phosphorescent OLEDs
}

\author{
Jungwoon Kim ${ }^{1}$, Suhan Lee ${ }^{2}$, Jaemin Lee ${ }^{3}{ }^{(0)}$, Eunhee Lim ${ }^{1, *}$ and Byung Jun Jung ${ }^{2, *}$ \\ 1 Department of Chemistry, Kyonggi University, 154-42 Gwanggyosanro, Yeongtong-gu, Suwon-si, \\ Gyeonggi 16227, Korea; 003polychem@gmail.com \\ 2 Department of Materials Science and Engineering, The University of Seoul, 163 Seoulsiripdaero, \\ Dongdaemun-gu, Seoul 02504, Korea; dltnghks88@nate.com \\ 3 Advanced Materials Division, Korea Research Institute of Chemical Technology (KRICT), 141 Gajeong-ro, \\ Yuseong-gu, Daejeon 34114, Korea; jminlee@krict.re.kr \\ * Correspondence: ehlim@kyonggi.ac.kr (E.L.); jungbj@uos.ac.kr (B.J.J.); \\ Tel.: +82-31-249-9663 (E.L.); +82-2-6490-2412 (B.J.J.)
}

Received: 20 March 2018; Accepted: 5 April 2018; Published: 8 April 2018

\begin{abstract}
Solution-processed organic light-emitting diodes (OLEDs) are attractive due to their low-cost, large area displays, and lighting features. Small molecules as well as polymers can be used as host materials within the solution-processed emitting layer. Herein, we report two 3,3'-bicarbazole-based host small molecules, which possess a structural isomer relationship. 9,9'-Di-4-n-butylphenyl-9H,9' $H$-3,3'-bicarbazole (BCz-nBuPh) and 9,9'-di-4-t-butylphenyl-9H, $9^{\prime} H$ 3,3'-bicarbazole (BCz-tBuPh) exhibited similar optical properties within solutions but different photoluminescence within films. A solution-processed green phosphorescent OLED with the BCz-tBuPh host exhibited a high maximum current efficiency and power efficiency of $43.1 \mathrm{~cd} / \mathrm{A}$ and $40.0 \mathrm{~lm} / \mathrm{W}$, respectively, compared to the device with the BCz-nBuPh host.
\end{abstract}

Keywords: solution-processed OLED; phosphorescent OLED; host; bicarbazole

\section{Introduction}

Ever since organic light-emitting diodes (OLEDs) were first reported by Tang and VanSlyke with an organometal compound of 8-hydroxyquinoline aluminum and an aromatic diamine compound [1], they have comprised the core technology of mobile and flat-panel displays. During the development of OLEDs, one great breakthrough was the utilization of a triplet emission called phosphorescence [2]. Ir complexes, such as phosphorescent dyes, exhibit a high phosphorescence yield at room temperature [3,4]. The external quantum efficiency of phosphorescent OLEDs (PHOLEDs) has exceeded that of fluorescent OLEDs [5]. In PHOLEDs, many carbazole molecules have been employed as host materials in the emitting layers [6,7]. As 4,4'-bis(N-carbazolyl)-1,1'-biphenyl (CBP) is a famous phosphorescent host molecule from early PHOLED reports [3,8], it has been employed as a general host material in studies pertaining to PHOLED materials and devices $[9,10]$.

Structural isomers possess different properties. 9,9'-Diphenyl-9H, $9^{\prime} \mathrm{H}-3,3^{\prime}$-bicarbazole (BCzPh), which was reported as a phosphorescent host in vacuum-deposited OLEDs by Sasabe et al. [11], is an isomer of CBP (Chart 1). BCzPh exhibits a higher glass transition temperature than CBP [11,12]. Bicarbazole derivatives have been studied as host materials [11,12], hole-transporting materials [13], and emitters $[14,15]$ in thermally activated delayed fluorescent (TADF) and exciplex OLEDs. Recently, solution-processed OLEDs have attracted considerable attention due to their low-cost and non-vacuum fabrication through methods such as ink-jet printing [16]. In solution-processed OLEDs, poly(9-vinylcarbazole) (PVK) is a typical host material $[17,18]$. Cai et al. reported that the small molecule CBP could be used as a good host material in solution-processed OLEDs [19]. 
In this paper, we report two structural isomers based on $3,3^{\prime}$-bicarbazole $(\mathbf{B C z})$ that have different alkyl groups (n-butyl and t-butyl groups) for solubility. 9,9'-Di-4-n-butylphenyl-9H,9' $H$ 3,3'-bicarbazole (BCz-nBuPh) and 9,9'-di-4-t-butylphenyl-9H,9' H-3,3'-bicarbazole (BCz-tBuPh) have the same molecular formula and molecular weight. However, they possess slightly different molecular structures. We investigated the thermal, optical, and electrochemical properties of the molecules as OLED host materials. Moreover, we evaluated solution-processed OLEDs using new host materials.

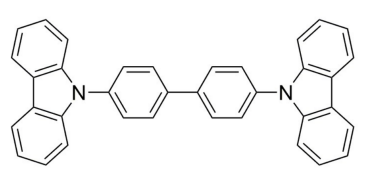

CBP

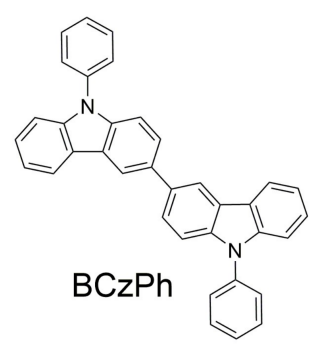

Chart 1. The chemical structures of $\mathrm{CBP}$ and $\mathrm{BCzPh}$.

\section{Results and Discussions}

\subsection{Synthesis and Thermal Analysis}

The synthetic routes and chemical structures for 3,3'-bicarbazole (BCz), BCz-nBuPh, and BCz-tBuPh can be seen in Scheme 1. Initially, 3,3'-bicarbazole was obtained via the chemical oxidative coupling of carbazoles in the presence of $\mathrm{FeCl}_{3}$ according to a procedure described in the literature [20]. Additionally, a detailed reduction procedure using zinc powder can be found in the materials section. The designed new host molecules, BCz-nBuPh and $\mathbf{B C z}-\mathbf{t B u P h}$, were synthesized through an Ullmann coupling reaction between 3,3'-bicarbazole and two iodobenzenes with n-butyl and t-butyl groups, respectively. The two compounds with alkyl groups were much more soluble in common organic solvents, such as chloroform and toluene, compared to the intermediate compound, BCz.

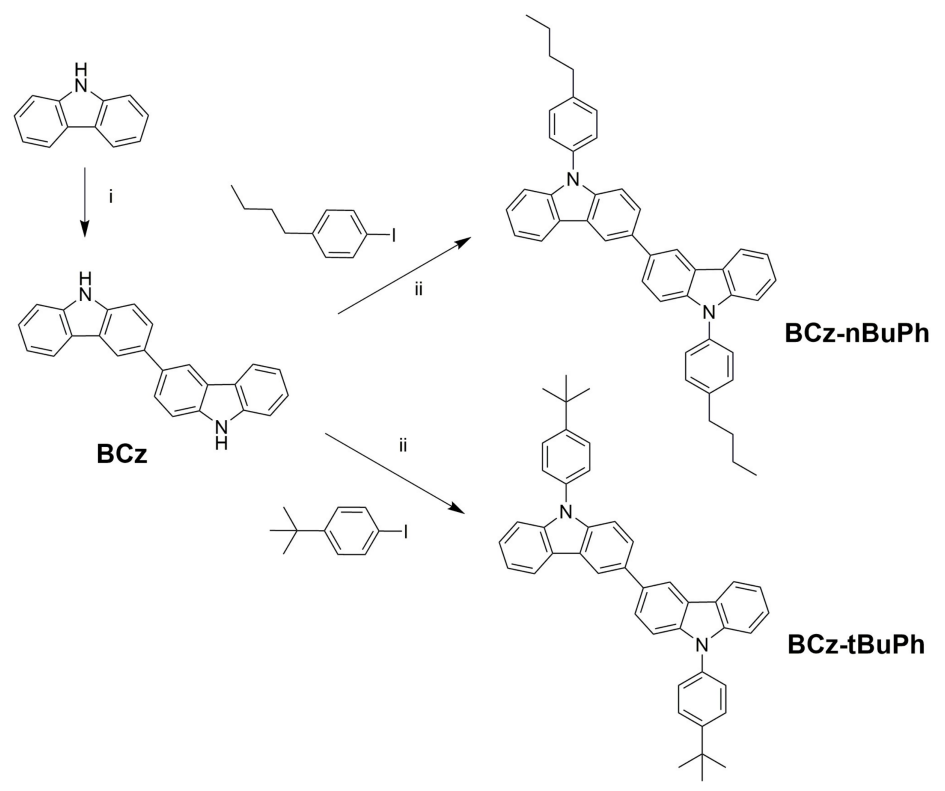

Scheme 1. The synthesis of host materials for solution processed organic light-emitting diodes (OLEDs). Reagents and conditions: (i) $\mathrm{FeCl}_{3}, \mathrm{CHCl}_{3}$, room temperature (RT); (ii) $\mathrm{Cu}, \mathrm{K}_{2} \mathrm{CO}_{3}, \mathrm{DMF}, 145^{\circ} \mathrm{C}$. 
Vacuum sublimation of the molecules yielded different aspects. BCz-nBuPh easily melted and then sublimed. BCz-tBuPh was sublimed as a powder and featured higher sublimation yields than BCz-nBuPh. The melting point and glass transition temperature of $\mathbf{B C z}-\mathbf{t B u P h}\left(295\right.$ and $136{ }^{\circ} \mathbf{C}$, respectively) was much higher than those of $\mathbf{B C z}-\mathbf{n B u P h}\left(146\right.$ and $58^{\circ} \mathrm{C}$, respectively) as can be seen in the differential scanning calorimetry (DSC) curves (Figure 1a). This difference could be attributed to the stiffness of the t-butyl group compared to the n-butyl group. In contrast to the melting points, thermal degradation of the two isomers was similar as can be seen in the thermogravimetric analysis (TGA) curves (Figure $1 \mathrm{~b}$ ). Both molecules were sufficiently stable up to $400{ }^{\circ} \mathrm{C}$; their thermal decomposition temperatures $\left(\mathrm{T}_{\mathrm{d}}\right)$ were $410{ }^{\circ} \mathrm{C}$ for $\mathbf{B C z}-\mathbf{n B u P h}$ and $423{ }^{\circ} \mathrm{C}$ for $\mathbf{B C z}-\mathbf{t B u P h}$.

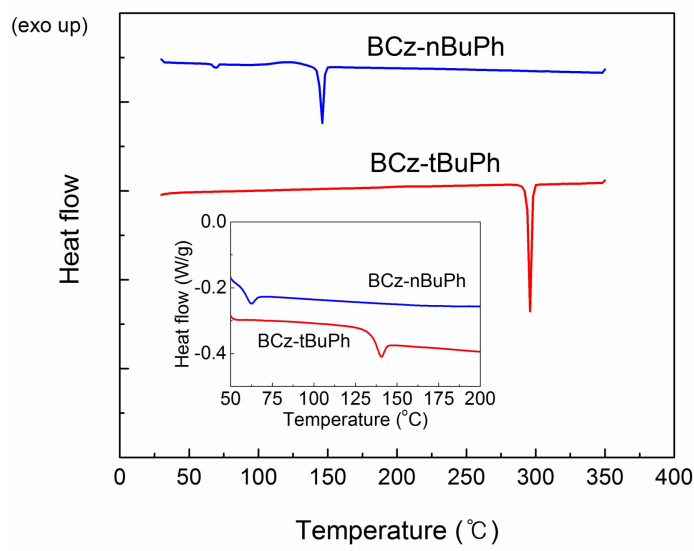

(a)

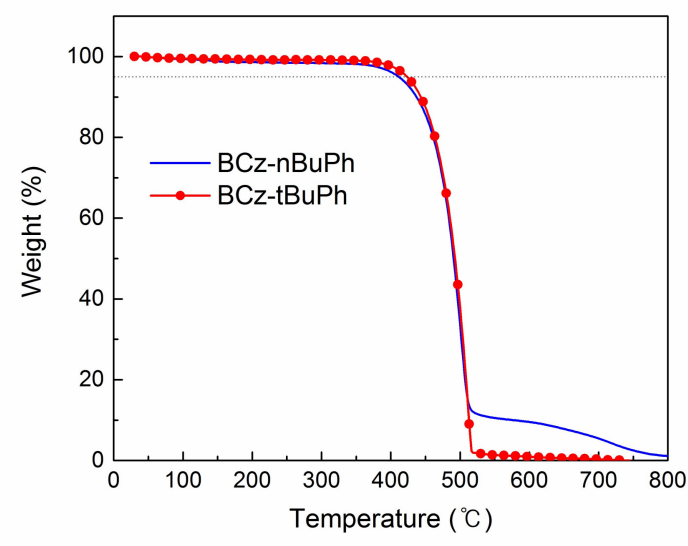

(b)

Figure 1. DSC curves on the first heating process (a) and the second heating process (inset) and TGA curves (b) of BCz-nBuPh and BCz-tBuPh.

\subsection{Photophyscial and Electrochemical Properties}

Figure 2 shows the UV-visible absorption and photoluminescence (PL) spectra of $\mathbf{B C z}-\mathbf{n B u P h}$ and BCz-tBuPh in dilute chloroform and as films. In the solution spectra (Figure 2a), the photophysical properties of the two isomers were nearly unchanged by the different alkyl groups. This meant that the two host materials possessed nearly the same optical properties from the $\pi-\pi^{*}$ transition of the same conjugated bicarbazole core.

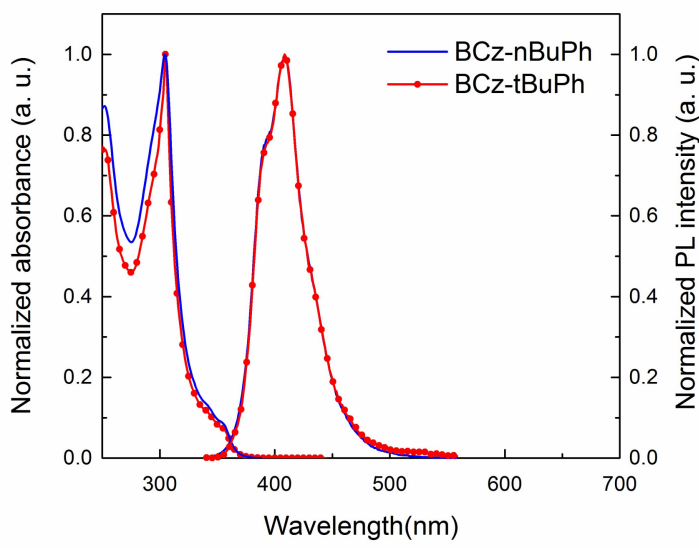

(a)

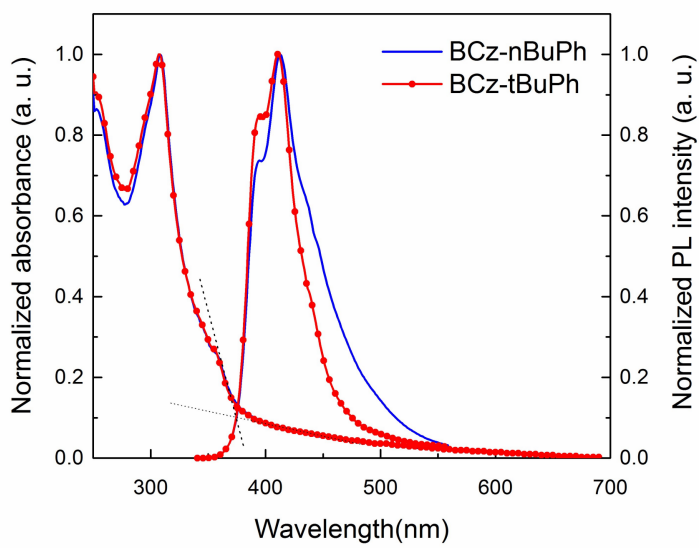

(b)

Figure 2. UV-visible absorption and photoluminescence (PL) spectra of $\mathbf{B C z}-\mathbf{n B u P h}$ and $\mathbf{B C z}-\mathbf{t B u P h}$ in solution (a) and in films (b). 
On the other hand, with regard to the film PL spectra (Figure 2b), BCz-nBuPh exhibited a relatively broad shoulder emission peak over $450 \mathrm{~nm}$ compared to BCz-tBuPh. Because the n-butyl group in $\mathbf{B C z}-\mathbf{n B u P h}$ exhibited less steric hindrance than the t-butyl group in $\mathbf{B C z}-\mathbf{t B u P h}$, molecules of $\mathbf{B C z}-\mathbf{n B u P h}$ within the film exhibited a strong degree of molecular aggregation. t-Butyl groups have been introduced to blue emitting molecules to prevent molecular quenching [21,22]. BCz-tBuPh with t-butyl groups was expected to yield better host materials than $\mathbf{B C z}-\mathbf{n B u P h}$ with regard to thermal and optical properties.

Optical band gaps were calculated from an absorption edge of $374 \mathrm{~nm}$ in the films, yielding values of $3.32 \mathrm{eV}$ for both BCz-nBuPh and BCz-tBuPh. This value was the same as that of BCzPh $(3.32 \mathrm{eV})[11]$ and enough to cover OLED dopants within visible light as the host materials.

The electrochemical properties of the two host molecules and $N, N^{\prime}$-bis(3-methyl-phenyl)$\left[1,1^{\prime}\right.$-biphenyl]-4,4'-diamine (TPD) were measured via cyclic voltammetry (CV) measurements (Figure 3). The ionization potential (IP) energy levels of the molecules were estimated according to an empirical relationship: $\mathrm{E}(\mathrm{IP})=\mathrm{E}_{[\mathrm{ox} \text {, onset vs. } \mathrm{Fc} / \mathrm{Fc}+]}+5.1(\mathrm{eV})[23-25]$, where $\mathrm{E}_{[\mathrm{ox} \text {, onset vs. } \mathrm{Fc} / \mathrm{Fc}+]}(\mathrm{V})$ is the onset potential of oxidation versus the redox potential of ferrocene/ferrocenium. The oxidation potentials of the two host molecules were almost the same. The IP energy levels were estimated to be $5.55 \mathrm{eV}$ for both BCz-nBuPh and BCz-tBuPh. The thermal, optical, and electrochemical properties of the molecules are summarized in Table 1.

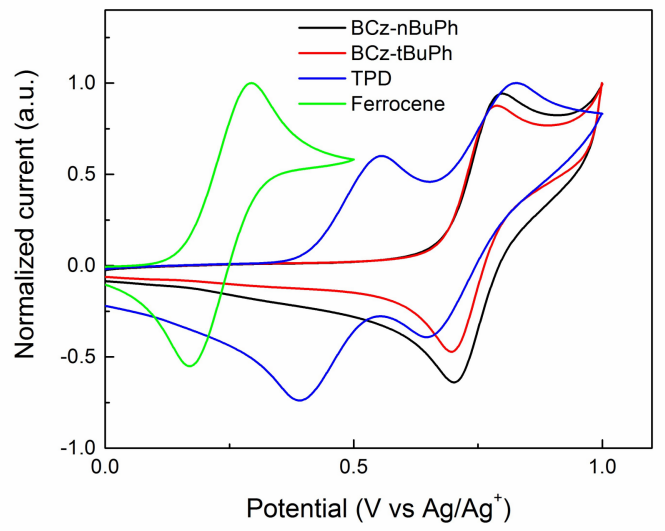

Figure 3. Cyclic voltammetry (CV) curves of BCz-nBuPh, BCz-tBuPh, and TPD in dichloromethane solution for oxidation.

Table 1. The thermal, optical, and electrochemical properties of BCz-nBuPh and BCz-tBuPh.

\begin{tabular}{|c|c|c|c|c|c|c|c|c|}
\hline $\begin{array}{c}\text { Host } \\
\text { Materials }\end{array}$ & $\begin{array}{c}\mathrm{T}_{\mathrm{m}} / \mathrm{T}_{\mathrm{g}}{ }^{\mathrm{a}} \\
\left({ }^{\circ} \mathrm{C}\right)\end{array}$ & $\mathrm{T}_{\mathrm{d}}{ }^{\mathrm{b}}\left({ }^{\mathrm{o}} \mathrm{C}\right)$ & $\begin{array}{c}\lambda_{\text {max, solution }}(\mathrm{nm}) \\
\text { UV-vis, PL }\end{array}$ & $\begin{array}{c}\lambda_{\max , \text { film }}(\mathrm{nm}) \\
\text { UV-vis, PL }\end{array}$ & $\mathrm{Eg}^{\mathrm{c}}(\mathrm{eV})$ & $\begin{array}{c}E_{\text {ox, onset }}{ }^{d} \\
\left(V \text { versus } \mathrm{Fc} / \mathrm{Fc}^{+}\right)\end{array}$ & $\mathrm{IP}^{\mathrm{e}}(\mathrm{eV})$ & $\mathrm{EA}^{\mathrm{f}}(\mathrm{eV})$ \\
\hline BCz-nBuPh & $146 / 58$ & 410 & 305,409 & 308,413 & 3.32 & 0.45 & 5.55 & 2.13 \\
\hline $\mathrm{BCz}-\mathrm{tBuPh}$ & $295 / 136$ & 423 & 304,409 & 308,411 & 3.32 & 0.45 & 5.55 & 2.13 \\
\hline
\end{tabular}

${ }^{a}$ Melting temperature and glass transition temperature, ${ }^{b}$ decomposition temperature corresponding to a $5 \%$ weight loss, ${ }^{\mathrm{c}}$ optical band gap, ${ }^{\mathrm{d}}$ Onset potential of oxidation versus ferrocene/ferrocenium redox system. ${ }^{\mathrm{e}}$ measured via $\mathrm{CV}$, ${ }^{\mathrm{f}}$ electron affinity as subtracting the optical bandgap from the ionization potential (IP).

\subsection{Solution-Processed OLEDs}

To evaluate the two host materials in solution-processed OLEDs, we fabricated green phosphorescent OLED devices using tris[2-(p-tolyl)pyridine]iridium(III) $\left(\operatorname{Ir}(\mathrm{mppy})_{3}\right)$ as a dopant. In vacuum-deposited OLEDs, tris[2-phenylpyridine]iridium(III) $\left(\operatorname{Ir}(\mathrm{ppy})_{3}\right)$ is usually used as a green dopant without solubility limits. In solution-processed OLEDs, $\operatorname{Ir}(\operatorname{mppy})_{3}$ is often used $[17,19,26]$. The emitting layer (EML) composition was host:TPD:PBD:Ir(mppy) $)_{3}$, where PBD is 2-(4-biphenylyl)-5-(4-tert-butylphenyl)-1,3,4-oxadiazole. TPD and PBD were blended to enhance the hole and electron transport properties of the EML, respectively. The weight ratios of each component 
were 61:9:24:6 according to the previous report for solution-processed OLEDs using PVK or CBP hosts [19].

The device configuration was indium tin oxide (ITO) $(150 \mathrm{~nm}) /$ poly(3,4-ethylenedioxy thiophene):poly(4-styrenesulfonate (PEDOT:PSS) (35 nm)/spin-coated EML (20 nm)/1,3,-bis(3,5dipyrid-3-yl-phenyl)benzene (BmPyPB) $(50 \mathrm{~nm}) / \mathrm{LiF}(0.7 \mathrm{~nm}) / \mathrm{Al}(70 \mathrm{~nm})$. As shown in Figure 4a, PHOLEDs using BCz-nBuPh and BCz-tBuPh exhibited green emission of $\operatorname{Ir}(\operatorname{mppy})_{3}$ with an emission maximum at $510 \mathrm{~nm}$. Figure $4 \mathrm{~b}-\mathrm{d}$ present OLED characteristics, such as the current density-voltage-luminance (J-V-L) curves and efficiency-luminance curves. Table 2 summarizes the OLED performance. Devices with BCz-tBuPh exhibited maximum current efficiency (CE), power efficiency (PE), and external quantum efficiency (EQE) values of $43.1 \mathrm{~cd} / \mathrm{A}, 40.0 \mathrm{~lm} / \mathrm{W}$, and $12.5 \%$, respectively; devices with $\mathbf{B C z}-\mathbf{n B u P h}$ exhibited values of $30.8 \mathrm{~cd} / \mathrm{A}, 28.1 \mathrm{~lm} / \mathrm{W}$, and $8.8 \%$, respectively. Moreover, devices with BCz-tBuPh exhibited a high current efficiency of $42.8 \mathrm{~cd} / \mathrm{A}$ and $38.8 \mathrm{~cd} / \mathrm{A}$ at 100 and $1000 \mathrm{~cd} / \mathrm{m}^{2}$ of the display-relevant luminance range, respectively. The efficiency of $\mathbf{B C z}-\mathbf{t B u P h}$ was lower than the highest reported efficiency in solution-processed green PHOLEDs, but comparable to the efficiency of devices based on several newly synthesized host materials $[18,27]$.

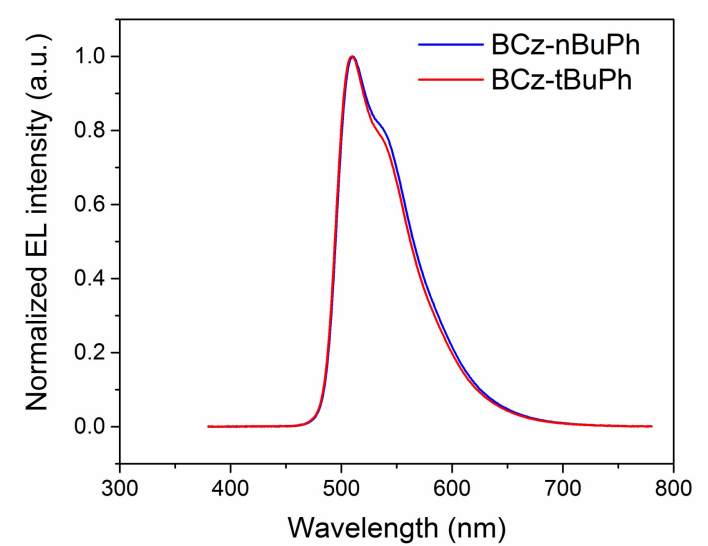

(a)

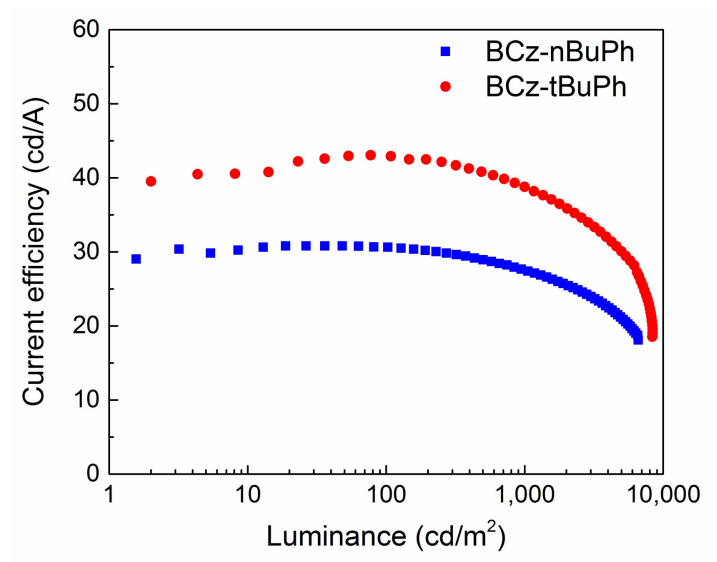

(c)

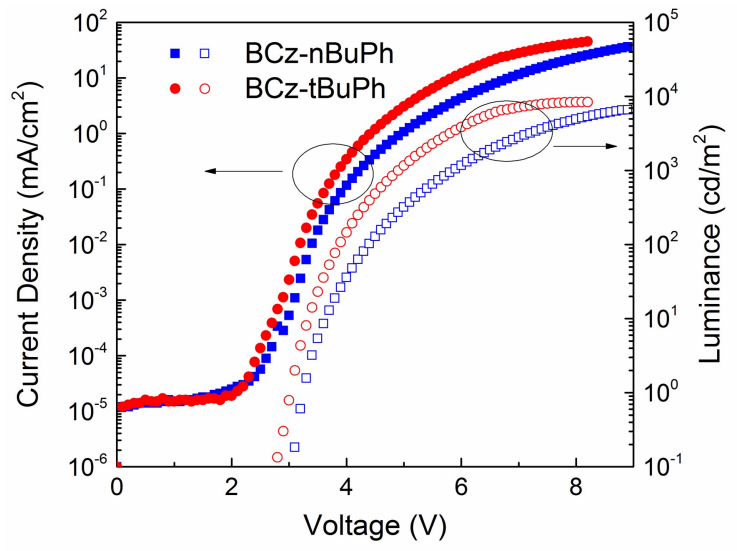

(b)

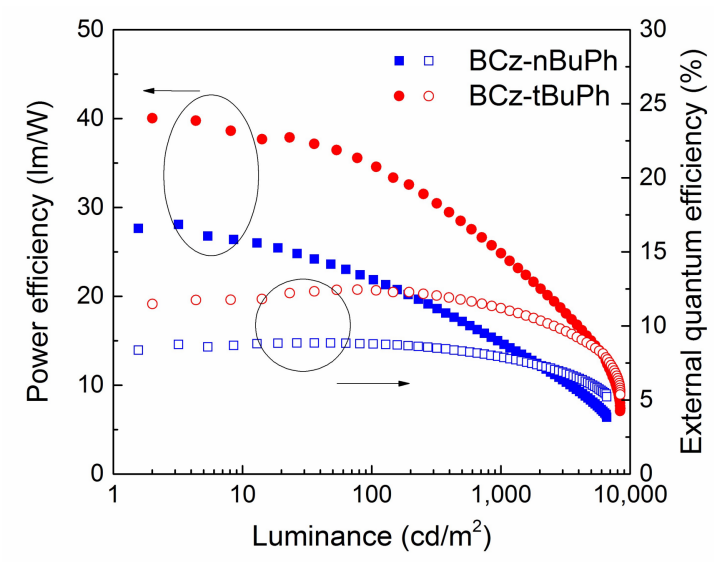

(d)

Figure 4. Electroluminescence (EL) spectra (a), current density-voltage-luminance (b), current efficiency-luminance (c), and power efficiency-luminance characteristics (d) of solution-processed green PHOLEDs using BCz-nBuPh and BCz-tBuPh, respectively. 
Table 2. The performance of solution-processed green PHOLEDs using BCz-nBuPh and BCz-tBuPh.

\begin{tabular}{|c|c|c|c|c|c|c|c|}
\hline $\begin{array}{c}\text { Host } \\
\text { Materials }\end{array}$ & $\lambda_{\mathrm{EL}}(\mathrm{nm})$ & $\operatorname{CIE}(x, y)^{a}$ & $\begin{array}{l}\mathrm{V}_{1}, \mathrm{~V}_{1000} \\
\quad(\mathrm{~V})^{\mathrm{b}}\end{array}$ & $\begin{array}{c}L_{\max }{ }^{c} \\
\left(\mathrm{~cd} / \mathrm{m}^{2}\right)\end{array}$ & $\begin{array}{c}C E \\
\max , 1000 \\
(c d / A)^{d}\end{array}$ & $\begin{array}{c}\text { PE } \\
\max , 1000 \\
(\operatorname{lm} / W)^{e}\end{array}$ & $\begin{array}{c}\text { EQE } \\
\max , 1000 \\
(\%)^{f}\end{array}$ \\
\hline BCz-nBuPh & 510 & $(0.301,0.620)$ & $3.3,5.8$ & 6598 & $30.8,27.6$ & $28.1,14.9$ & 8.8. 7.9 \\
\hline $\mathrm{BCz}-\mathrm{tBuPh}$ & 510 & $(0.294,0.621)$ & $3.1,4.9$ & 8372 & $43.1,38.8$ & $40.0,24.9$ & 12.5. 11.2 \\
\hline
\end{tabular}

a Commission International deI'Eclairage (CIE) coordinates, ${ }^{\mathrm{b}}$ driving voltage at a luminance of $1 \mathrm{~cd} / \mathrm{m}^{2}$ and $1000 \mathrm{~cd} / \mathrm{m}^{2},{ }^{d}$ maximum current efficiency (CE) and CE at $1000 \mathrm{~cd} / \mathrm{m}^{2},{ }^{\mathrm{e}}$ maximum power efficiency (PE) and PE at $1000 \mathrm{~cd} / \mathrm{m}^{2}$, e maximum external quantum efficiency (EQE) and EQE at $1000 \mathrm{~cd} / \mathrm{m}^{2}$.

As can be seen in Figure 4c,d, BCz-tBuPh exhibited superior efficiency compared to BCz-nBuPh at all degrees of luminance. This result could be attributed to a difference in effective transfer from the host to dopant. As BCz-tBuPh with t-butyl groups did not exhibit aggregation emission in the film PL spectrum, the material served a better host role in OLED devices compared to BCz-nBuPh. Further device works, such as the reports of other host materials [28,29], will be reported elsewhere.

\section{Materials and Methods}

\subsection{General Procedures}

Carbazole, potassium carbonate $\left(\mathrm{K}_{2} \mathrm{CO}_{3}\right)$, copper, iodobenzene, chloroform, and dimethylformamide (DMF) were purchased from Aldrich (St. Louis, MO, USA). 1-N-butyl-4iodobenzene, 1-t-butyl-4-iodobenzene, and $\mathrm{FeCl}_{3}$ were purchased from Aldrich (St. Louis, MO, USA). Zinc powder, ethyl acetate, and acetic acid were purchased Showa chemical Inc. (Tokyo, Japan), Duksan (Seoul, Korea), and Samchun (Seoul, Korea), respectively. All commercial reagents were used as-is without further purification.

NMR spectra were recorded on a Bruker AVANCE II 400 spectrometer (Billerica, MA, USA). UV-vis spectra were obtained using a UV-Vis spectrophotometer (UV-3150, Shimadzu, Kyoto, Japan). Photoluminescence (PL) spectra were obtained using a F-4500 fluorescence spectrophotometer (Hitachi, Tokyo, Japan). Films of small molecules used for the UV-vis and PL measurements were prepared via solution spin-coating. Optical energy band gaps $\left(\mathrm{E}_{\mathrm{g}}\right)$ were estimated from the absorption onset wavelengths $\left(\mathrm{E}_{\mathrm{g}}(\mathrm{eV})=1240 / \lambda_{\text {onset }}\right)$ of the small molecule films. Differential scanning calorimetry (DSC) and thermogravimetric analysis (TGA) were performed with a differential scanning calorimeter (DSC 1, Mettler Toledo, Columbus, OH, USA) and TGA Q500 (TA instruments, New Castle, DE, USA), respectively. Cyclic voltammetry (CV) data was obtained with a BAS $100 \mathrm{~B}$ electrochemical analyzer (Bioanalytical Systems, West Lafayette, IN, USA).

\subsection{Synthesis}

\subsubsection{3,3'-bicarbazole $(\mathbf{B C z})$}

Carbazole (12.0 g, $72.0 \mathrm{mmol})$ and anhydrous $\mathrm{FeCl}_{3}(47.0 \mathrm{~g}, 288 \mathrm{mmol})$ were dissolved in $240 \mathrm{~mL}$ of chloroform and stirred for $30 \mathrm{~min}$ under nitrogen. The solution was subsequently poured into a larger quantity of methyl alcohol. The precipitated green powder and zinc powder (18.7 g, $288 \mathrm{mmol})$ were dissolved in a solution of acetic acid and ethyl acetate $(180 \mathrm{~mL}, 1: 1)$ under nitrogen. The mixture was heated at $50{ }^{\circ} \mathrm{C}$ overnight. The reaction mixture was filtered and washed with hot ethyl acetate. The filtered solution was poured into water and extracted with ethyl acetate. The organics were combined, washed with brine, and dried with sodium sulfate. After solvent removal, $5.94 \mathrm{~g}$ of a brown powder was obtained. This crude product was purified via vacuum sublimation. Obtained as a while solid was $2.53 \mathrm{~g}(8.0 \mathrm{mmol}, 22 \%)$ of BCz. ${ }^{1} \mathrm{H}-\mathrm{NMR}\left(400 \mathrm{MHz}, \mathrm{DMSO}-d_{6}\right): \delta(\mathrm{ppm}) 11.28(\mathrm{~s}, 2 \mathrm{H}), 8.51$ $(\mathrm{s}, 2 \mathrm{H}), 8.25(\mathrm{~d}, J=7.7 \mathrm{~Hz}, 2 \mathrm{H}), 7.81(\mathrm{dd}, J=8.4 \mathrm{~Hz}, J=1.4 \mathrm{~Hz}, 2 \mathrm{H}), 7.58(\mathrm{~d}, J=8.4 \mathrm{~Hz}, 2 \mathrm{H}), 7.51(\mathrm{~d}$, $J=8.1 \mathrm{~Hz}, 2 \mathrm{H}), 7.41(\mathrm{t}, J=7.6 \mathrm{~Hz}, 2 \mathrm{H}), 7.19(\mathrm{t}, J=7.4 \mathrm{~Hz}, 2 \mathrm{H}) .{ }^{13} \mathrm{C}-\mathrm{NMR}\left(100 \mathrm{MHz}\right.$, DMSO- $\left.d_{6}\right): \delta(\mathrm{ppm})$ $140.7,139.2,132.8,126.1,125.4,123.6,123.2,120.9,119.0,118.6,111.7,111.5$. 


\subsubsection{9,9'-di-4-n-butylphenyl-9H, $9^{\prime} H-3,3$ '-bicarbazole (BCz-nBuPh)}

3,3'-Bicarbazole (1.5 g, $4.5 \mathrm{mmol}), 1$-n-butyl-4-iodobenzene ( $2.5 \mathrm{~mL}, 18 \mathrm{mmol})$, copper powder $(1.70 \mathrm{~g}, 27.1 \mathrm{mmol})$, and $\mathrm{K}_{2} \mathrm{CO}_{3}(3.73 \mathrm{~g}, 27.1 \mathrm{mmol})$ were dissolved in $10 \mathrm{~mL}$ of anhydrous DMF under nitrogen. After heating the mixture at $145^{\circ} \mathrm{C}$ overnight, the reaction solution was filtered through a plug of celite. The filtered solution was poured into water and extracted with chloroform. The organics were combined, washed with brine, and dried with sodium sulfate. After solvent removal, the product was purified via column chromatography with 1:1 $(v / v)$ dichloromethane-hexane as the eluent to yield $1.41 \mathrm{~g}(2.36 \mathrm{mmol}, 52 \%)$ of BCz-nBuPh as a white solid. For OLED devices, the product was further purified twice via vacuum sublimation. The sublimation yield was $33 \%$. Mp $146{ }^{\circ} \mathrm{C} .{ }^{1} \mathrm{H}-\mathrm{NMR}$ $\left(400 \mathrm{MHz}, \mathrm{CDCl}_{3}\right): \delta(\mathrm{ppm}) 8.45(\mathrm{~s}, 2 \mathrm{H}), 8.23(\mathrm{~d}, J=7.7 \mathrm{~Hz}, 2 \mathrm{H}), 7.77(\mathrm{dd}, J=8.5 \mathrm{~Hz}, J=1.6 \mathrm{~Hz}, 2 \mathrm{H})$, 7.52-7.49 (m, 6H), 7.44-7.42 (m, 8H), 7.32-7.30 (m, 2H), $2.76(\mathrm{~d}, J=7.6 \mathrm{~Hz}, 4 \mathrm{H}), 1.77-1.69(\mathrm{~m}, 4 \mathrm{H})$, 1.51-1.42 (m, 4H), $1.01(\mathrm{t}, J=7.3 \mathrm{~Hz}, 6 \mathrm{H}) .{ }^{13} \mathrm{C}-\mathrm{NMR}\left(100 \mathrm{MHz}, \mathrm{CDCl}_{3}\right): \delta(\mathrm{ppm}) 142.3,141.5,140.2$, 135.2, 134.3, 129.8, 126.9, 126.0, 125.8, 123.9, 123.5, 120.4, 119.8, 118.9, 110.1 101.0, 35.4, 33.7, 22.5, 14.1 . Anal. calcd. for $\mathrm{C}_{44} \mathrm{H}_{40} \mathrm{~N}_{2}$ (\%): C, 88.55; H, 6.76; N, 4.69; found: C, 88.07; H, 7.00; N, 4.80\%.

\subsubsection{9,9'-di-4-t-butylphenyl-9H, $9^{\prime} H-3,3^{\prime}$-bicarbazole (BCz-tBuPh)}

3,3'-Bicarbazole (1.0 g, $3 \mathrm{mmol})$, 1-t-butyl-4-iodobenzene ( $2.06 \mathrm{~mL}, 11.5 \mathrm{mmol})$, copper powder $(1.1 \mathrm{~g}, 17 \mathrm{mmol})$, and $\mathrm{K}_{2} \mathrm{CO}_{3}(2.4 \mathrm{~g}, 17 \mathrm{mmol})$ were dissolved in $10 \mathrm{~mL}$ of anhydrous DMF under nitrogen. After heating the mixture at $145^{\circ} \mathrm{C}$ overnight, the reaction solution was filtered through a plug of celite. The filtered solution was poured into water and extracted with chloroform. The organics were combined, washed with brine, and dried with sodium sulfate. After solvent removal, the product was purified via column chromatography with 1:2 $(v / v)$ chloroform-hexane as the eluent to yield $1.23 \mathrm{~g}$ (2.01 mmol, 69\%) of BCz-tBuPh as a white solid. For OLED devices, the product was further purified twice via vacuum sublimation. The sublimation yield was $74 \%$. Mp $295{ }^{\circ} \mathrm{C} .{ }^{1} \mathrm{H}-\mathrm{NMR}(400 \mathrm{MHz}$, $\left.\mathrm{CDCl}_{3}\right): \delta(\mathrm{ppm}) 8.45(\mathrm{~d}, J=1.4 \mathrm{~Hz}, 2 \mathrm{H}), 8.24(\mathrm{~d}, J=7.7 \mathrm{~Hz}, 2 \mathrm{H}), 7.77(\mathrm{dd}, J=8.5 \mathrm{~Hz}, J=1.8 \mathrm{~Hz}, 2 \mathrm{H})$, 7.65-7.62 (m, 4H), 7.56-7.52 (m, 6H), 7.48-7.41 (m, 4H), 7.33-7.29 (m, 2H), $1.45(\mathrm{~s}, 18 \mathrm{H}) .{ }^{13} \mathrm{C}-\mathrm{NMR}$ $\left(100 \mathrm{MHz}, \mathrm{CDCl}_{3}\right): \delta$ (ppm) 150.4, 141.5, 140.1, 135.0, 134.3, 126.8, 126.5, 125.9, 125.8, 123.9, 123.5, 120.4, $119.8,118.9,110.2,110.0,34.8,31.5$. Anal. calcd. for $\mathrm{C}_{44} \mathrm{H}_{40} \mathrm{~N}_{2}$ : $\mathrm{C}, 88.55 ; \mathrm{H}, 6.76 ; \mathrm{N}, 4.69$; found: $\mathrm{C}$, $88.00 ; \mathrm{H}, 6.84 ; \mathrm{N}, 4.80 \%$.

\subsection{Device Fabrication and Characterization}

Pre-patterned indium tin oxide (ITO) glass substrates were cleaned via ultrasonication with acetone, isopropyl alcohol, and deionized water. The substrates were treated with ultraviolet-ozone for 20 min using a UV-ozone cleaner (AH1700, AHTECH LTS Co., Ltd., Anyang, Gyeonggi, Korea). The poly(3,4-ethylenedioxy thiophene):poly(4-styrenesulfonate) (PEDOT:PSS, AI 4083, Heraeus, Hanau, Germany) solution was filtered through a $0.45 \mu \mathrm{m}$ PVDF syringe filter and spin-coated at $4000 \mathrm{rpm}$ for $40 \mathrm{~s}$ to form the hole-injection layer (HIL) onto ITO substrates. The PEDOT:PSS-coated substrates were placed onto a hotplate at $150{ }^{\circ} \mathrm{C}$ for $30 \mathrm{~min}$ under air. Prior to depositing the emissive layer (EML), a $1 \mathrm{wt}$. \% chlorobenzene solution was prepared in the weight ratio of 61:9:24:6 for BCz-nBuPh:TPD:PBD:Ir(mppy) ${ }_{3}$ and BCz-tBuPh:TPD:PBD:Ir(mppy) $)_{3}$ and stirred at $70{ }^{\circ} \mathrm{C}$ for $1 \mathrm{~h}$. The solutions were subsequently filtered through a $0.45 \mu \mathrm{m}$ PTFE syringe filter; the EML was spin-coated onto the HIL-coated substrate at $2500 \mathrm{rpm}$ for $60 \mathrm{~s}$ under nitrogen. Thereafter, the electron-transporting layer of $\mathrm{BmPyPB}$, the electron injection layer of $\mathrm{LiF}$, and the $\mathrm{Al}$ cathode were deposited via thermal evaporation in a vacuum chamber under $5 \times 10^{-7}$ torr. The OLED devices were encapsulated with a glass lid, a moisture getter, and epoxy glue in a glove box. The current-voltage-luminance characteristics of the OLEDs were obtained with a Keithley 2400 source meter (Cleveland, OH, USA) and a Konica Minola CS-2000 spectroradiometer (Tokyo, Japan) in air. 


\section{Conclusions}

We synthesized 3,3'-bicarbazole-based molecules, BCz-nBuPh and BCz-tBuPh, for phosphorescent OLED host materials through an Ullmann coupling reaction between $3,3^{\prime}$-bicarbazole and iodobenzne with n-butyl and t-butyl groups. BCz-nBuPh exhibited a low melting point of $146^{\circ} \mathrm{C}$ compared to $295^{\circ} \mathrm{C}$ for BCz-tBuPh. Molecular aggregation emission was observed in the PL spectra of the BCz-nBuPh films. BCz-tBuPh did not exhibit aggregation emission in the solid state and was more suitable as a host material in solution-processed EMLs compared to $\mathbf{B C z}-\mathbf{n B u P h}$, exhibiting a maximum current efficiency of $43.1 \mathrm{~cd} / \mathrm{A}$ with a high current efficiency of $38.8 \mathrm{~cd} / \mathrm{A}$ at $1000 \mathrm{~cd} / \mathrm{m}^{2}$ for green PHOLEDs.

Acknowledgments: This work was supported by the 2014 Research Fund of the University of Seoul for Byung Jun Jung.

Author Contributions: J.L., E.L. and B.J.J. designed the research; J.K. performed the synthesis and characterization of molecules under supervision of E.L.; Thermal and electrochemical analysis was conducted by J.K. and J.L.; OLED fabrication was performed by S.L.; J.K. and B.J.J wrote the manuscript.

Conflicts of Interest: The authors declare no conflict of interest.

\section{References}

1. Tang, C.W.; VanSlyke, S.A. Organic electroluminescent diodes. Appl. Phys. Lett. 1987, 51, 913-915. [CrossRef]

2. Baldo, M.A.; O’Brien, D.F.; You, Y.; Shoustikov, A.; Sibley, S.; Thompson, M.E.; Forrest, S.R. Highly efficient phosphorescent emission from organic electroluminescent devices. Nature 1998, 395, 151-154. [CrossRef]

3. Lamansky, S.; Djurovich, P.; Murphy, D.; Abdel-Razzaq, F.; Lee, H.E.; Adachi, C.; Burrows, P.E.; Forrest, S.R.; Thompson, M.E. Highly Phosphorescent Bis-Cyclometalated Iridium Complexes: Synthesis, Photophysical Characterization, and Use in Organic Light Emitting Diodes. J. Am. Chem. Soc. 2001, 123, 4304-4312. [CrossRef] [PubMed]

4. You, Y.; Park, S.Y. Phosphorescent iridium(III) complexes: Toward high phosphorescence quantum efficiency through ligand control. Dalton Trans. 2009, 1267-1282.

5. Murawski, C.; Leo, K.; Gather, M.C. Efficiency Roll-Off in Organic Light-Emitting Diodes. Adv. Mater. 2013, 25, 6801-6827. [CrossRef] [PubMed]

6. Jou, J.H.; Kumar, S.; Agrawal, A.; Li, T.H.; Sahoo, S. Approaches for fabricating high efficiency organic light emitting diodes. J. Mater. Chem. C 2015, 3, 2974-3002. [CrossRef]

7. Yang, T.; Xu, H.; Zhao, B.; Tao, P.; Sun, P.; Wang, H.; Xu, B.; Wong, W. Three carbazole-based host materials: facile synthesis, photophysical properties and performances in PhOLED. Tetrahedron 2016, 72, 8066-8072. [CrossRef]

8. $\quad$ Baldo, M.A.; Lamansky, S.; Burrows, P.E.; Thompson, M.E.; Forrest, S.R. Very High-Efficiency Green Organic Light-Emitting Devices Based on Electrophosphorescence. Appl. Phys. Lett. 1999, 75, 4-6. [CrossRef]

9. Jayabharathi, J.; Thanikachalam, V.; Sathishkumar, R. Highly Phosphorescent Green Emitting Iridium(III) Complexes for Application in OLEDs. New J. Chem. 2015, 39, 235-245. [CrossRef]

10. Yu, H.; Zhang, Y.; Cho, Y.J.; Aziz, H. Exciton-Induced Degradation of Carbazole-Based Host Materials and Its Role in the Electroluminescence Spectral Changes in Phosphorescent Organic Light Emitting Devices with Electrical Aging. ACS Appl. Mater. Interfaces 2017, 9, 14145-14152. [CrossRef] [PubMed]

11. Sasabe, H.; Toyota, N.; Nakanishi, H.; Ishizaka, T.; Pu, Y.J.; Kido, J. 3,3'-Bicarbazole-Based Host Materials for High-Efficiency Blue Phosphorescent OLEDs with Extremely Low Driving Voltage. Adv. Mater. 2012, 24, 3212-3217. [CrossRef] [PubMed]

12. Tsai, M.-H.; Hong, Y.-H.; Chang, C.-H.; Su, H.-C.; Wu, C.C.; Matoliukstyte, A.; Simokaitiene, J.; Grigalevicius, S.; Grazulevicius, J.V.; Hsu, C.-P. 3-(9-Carbazolyl)carbazoles and 3,6-Di(9-carbazolyl)carbazoles as Effective Host Materials for Efficient Blue Organic Electrophosphorescence. Adv. Mater. 2007, 19, 862-866. [CrossRef]

13. Ameen, S.; Lee, J.; Han, H.; Suh, M.C.; Lee, C. Curing Temperature Reduction and Performance Improvement of Solution processable Hole-transporting Materials for Phosphorescent OLEDs by Manipulation of Cross-linking Functionalities and Core Structures. RSC Adv. 2016, 6, 33212-33220. [CrossRef] 
14. Kim, M.; Jeon, S.K.; Hwang, S.-H.; Lee, S.-S.; Yu, E.; Lee, J.Y. Correlation of Molecular Structure with Photophysical Properties and Device Performances of Thermally Activated Delayed Fluorescent Emitters. J. Phys. Chem. C 2016, 120, 2485-2493. [CrossRef]

15. Grybauskaite-Kaminskiene, G.; Ivaniuk, K.; Bagdziunas, G.; Turyk, P.; Stakhira, P.; Baryshnikov, G.; Volyniuk, D.; Cherpak, V.; Minaev, B.; Hotra, Z.; et al. Contribution of TADF and exciplex emission for efficient "warm-white" OLEDs. J. Mater. Chem. C 2018, 6, 1543-1550. [CrossRef]

16. Ahn, S.I.; Kim, W.K.; Ryu, S.H.; Kim, K.J.; Lee, S.E.; Kim, S.H.; Park, J.C.; Choi, K.C. OLED with a Controlled Molecular Weight of the PVK (Poly(9-vinylcarbazole)) Formed by a Reactive Ink-Jet Process. Org. Electron. 2012, 13, 980-984. [CrossRef]

17. Choulis, S.A.; Choong, V.-E.; Mathai, M.K.; So, F. The effect of interfacial layer on the performance of organic light-emitting diodes. Appl. Phys. Lett. 2005, 87, 113503. [CrossRef]

18. Yook, K.S.; Lee, J.Y. Small Molecule Host Materials for Solution Processed Phosphorescent Organic Light-Emitting Diodes. Adv. Mater. 2014, 26, 4218-4233. [CrossRef] [PubMed]

19. Cai, M.; Xiao, T.; Hellerich, E.; Chen, Y.; Shinar, R.; Shinar, J. High-Efficiency Solution-Processed Small Molecule Electrophosphorescent Organic Light-Emitting Diodes. Adv. Mater. 2011, 23, 3590-3596. [CrossRef] [PubMed]

20. Gao, Y.; Hlil, A.; Wang, J.; Chen, K.; Hay, A. Synthesis of Homo- and Copoly(arylene bicarbazole)s via Nucleophilic Substitution Polycondensation Reactions of NH Groups with Activated Dihalides. Macromolecules 2007, 40, 4744-4746. [CrossRef]

21. Zhang, G.; Auer-Berger, M.; Gehrig, D.W.; Blom, P.W.M.; Baumgarten, M.; Schollmeyer, D.; List-Kratochvil, E.J.W.; Müllen, K. Blue Light Emitting Polyphenylene Dendrimers with Bipolar Charge Transport Moieties. Molecules 2016, 21, 1400. [CrossRef] [PubMed]

22. Yang, J.; Qin, J.; Ren, Z.; Peng, Q.; Xie, G.; Li, Z. Pyrene-Based Blue AIEgen: Enhanced Hole Mobility and Good EL Performance in Solution-Processed OLEDs. Molecules 2017, 22, 2144. [CrossRef] [PubMed]

23. Cardona, C.M.; Li, W.; Kaifer, A.E.; Stockdale, D.; Bazan, G.C. Electrochemical Considerations for Determining Absolute Frontier Orbital Energy Levels of Conjugated Polymers for Solar Cell Applications. Adv. Mater. 2011, 23, 2367-2371. [CrossRef] [PubMed]

24. Fitzner, R.; Mena-Osteritz, E.; Walzer, K.; Pfeiffer, M.; Bäuerle, P. A-D-A-Type Oligothiophenes for Small Molecule Organic Solar Cells: Extending the $\pi$-System by Introduction of Ring-Locked Double Bonds. Adv. Funct. Mater. 2015, 25, 1845-1856. [CrossRef]

25. Chen, Z.; Liu, X.-K.; Zheng, C.-J.; Ye, J.; Liu, C.-L.; Li, F.; Ou, X.-M.; Lee, C.-S.; Zhang, X.-H. High Performance Exciplex-Based Fluorescence-Phosphorescence White Organic Light-Emitting Device with Highly Simplified Structure. Chem. Mater. 2015, 27, 5206-5211. [CrossRef]

26. Li, H.; Tao, Y.; Chen, R.; Xie, G.; Zheng, C.; Huang, W. Carbazole/Oligofluorene End-Capped Hexanes: Solution-processable Host Materials for Phosphorescent Organic Light-Emitting Diodes. J. Mater. Chem. C 2017, 5, 4442-4447. [CrossRef]

27. Lin, W.-C.; Lin, H.-W.; Mondal, E.; Wong, K.-T. Efficient Solution-Processed Green and White Phosphorescence Organic Light-Emitting Diodes Based on Bipolar Host Materials. Org. Electron. 2015, 17, 1-8. [CrossRef]

28. Bagdžiūnas, G.; Grybauskaitè, G.; Kostiv, N.; Ivaniuk, K.; Volyniuk, D.; Lazauskas, A. Green and red phosphorescent organic light-emitting diodes with ambipolar hosts based on phenothiazine and carbazole moieties: Photoelectrical properties, morphology and efficiency. RSC Adv. 2016, 6, 61544-61554.

29. Reig, M.; Bagdziunas, G.; Volyniuk, D.; Grazulevicius, J.V.; Velasco, D. Tuning the ambipolar charge transport properties of tricyanovinyl-substituted carbazole-based materials. Phys. Chem. Chem. Phys. 2017, 19, 6721-6730. [CrossRef] [PubMed]

Sample Availability: Samples of the compounds are not available from the authors. 